https://doi.org/10.32870/dgedj.v0i5.73

\title{
La influencia de la Función Jurisdiccional en la Implementación de Políticas Públicas
}

\author{
El derecho es el río en la que nadan los \\ administradores públicos y la \\ interpretación de aquel que realizan los \\ tribunales, constituye el sentido de la \\ corrientel.
}

\section{Alfonso Christian Martínez Pabello*}

Recibido: 24 octubre 2016

\section{Resumen}

Siendo la encarga de garantizar la prevalencia de las normas del Estado, la función esencial de la jurisdicción dentro de las Políticas Públicas, es la de constituirse en poder equilibrador entre el legislativo y el ejecutivo, controlando la observancia de las esferas competenciales, aunado a esto, mantiene la supremacía de la constitución vigilando que se respeten los procedimientos de elaboración de las leyes, y subordinando el orden jurídico a la norma fundamental.

Palabras clave: Políticas públicas, Función Jurisdiccional, Corte Constitucional, Derechos Fundamentales

\section{The influence of the jurisdictional function in the implementation of public policies}

\begin{abstract}
Being responsible for guaranteeing the prevalence of State rules, the essential function of

*alfonsopabello@gmail.com Instituto Tecnológico de estudios Superiores de Monterrey.

1 Reflexión propia, basada en la lectura del "El impacto de los tribunales sobre la gestión pública" O'Leary Rosemary, Straussman; Jeffrey D; Barry Bozeman: La gestión Pública. Su situación Actual. Fondo de Cultura
\end{abstract} Económica. México. 2006 
jurisdiction within Public Policies is to be a balance between the legislative and the executive, controlling the observance of the spheres of competence, along with this , Maintains the supremacy of the constitution by ensuring that the procedures for drafting the laws are respected, and subordinating the legal order to the fundamental norm.

Key words: Public Policies, Jurisdictional Function, Constitutional Court, Fundamental Right

\section{Sumario}

I. Introducción. II. Las políticas públicas. III. La función jurisdiccional dentro de las políticas públicas. IV. Las sentencias en el ámbito de las políticas públicas. V. Núcleo esencial de los derechos fundamentales. VI. Amparo en revisión 323/2014 -mexicanos primero vs auditoría superior de la federación. VII. Amparo en revisión 44/2009 -issteleon y sus políticas discriminatorias-. VIII. Acción pública de inconstitucionalidad c355/2006 de la Corte Constitucional de Colombia -despenalización del aborto-. IX. Conclusiones. Bibliografía.

\section{Introducción}

Polibio, John Locke y Montesquieu, en su conjunto, son un sinónimo usado a manera de sello en todo artículo, tesis o estudio que verse sobre la teoría de división de poderes.

Sin embargo, sus aportaciones y las diversas contribuciones posteriores relacionadas al control del poder, se limitan a establecer la necesidad e importancia de la distribución de potestades dentro de un Estado, en casos más modernos, dentro del Estado Constitucional de Derecho; por lo que se han hecho pocas incursiones acerca de las formas específicas en que una función de gobierno puede tener influencia o impacto en otra, es decir, acerca de cómo se dan los controles del poder y sus consecuencias relacionadas al garantizar la libertad dentro de un estado, un ejemplo de esto es la "Judicialización de los Derechos" fenómeno por medio del cual los ciudadanos exigen derechos a través de mecanismos jurisdiccionales.

En este sentido el presente trabajo tiene la finalidad de analizar de manera específica una de las relaciones de control entre funciones de gobierno, la derivada 
entre las sentencias y las políticas públicas.

\section{Las Políticas Públicas}

Se parte en el presente estudio definiendo a las políticas públicas, para lo cual se utiliza la definición del profesor Aguilar Villanueva, al considerarse una de las más completas para entender esta compleja disciplina:

"Una política pública es: a) un conjunto (secuencia, sistema, ciclo) de acciones, estructuradas en modo intencional y causal, que se orientan a realizar objetivos considerados de valor para la sociedad o a resolver problemas cuya solución es considerada de interés o beneficio público; b) acciones cuya intencionalidad y causalidad han sido definidas por la interlocución que ha tenido lugar entre el gobierno y los sectores de la ciudadania; c) acciones que han sido decididas por autoridades públicas legitimas; d) acciones que son ejecutadas por actores gubernamentales o por éstos en asociación con actores sociales (económicos, civiles), y e) que dan origen o forman un patrón de comportamiento del gobierno y la sociedad ${ }^{2}$.

En este sentido es posible comprender que las Políticas Públicas, son la materialización de los planes de la Administración pública en busca de darle solución, a priori y a posteriori, a alguna o algunas problemáticas que se susciten entre la población.

En otras palabras, la administración pública, tiene una función de guía del Estado respecto a los intereses trazados, por lo que constituyen un indicador que puede medir las transformaciones del Estado, esto a través de las políticas públicas.

De lo anterior se desprende que las políticas públicas cumplen un papel protagónico en la vida y el desarrollo del Estado, ya que todo aquello que hay o no hay en el mismo es resultado de los procesos de diseño e implementación.

Se identifica que tienen cuatro aspectos esenciales indispensables de

2 Aguilar, Luis F. (2009) Marco para el análisis de las políticas públicas. En Mariñez, Freddy y Garza, Vidal (2009) Política pública y democracia en América Latina del análisis a la implementación. Porrúa, México, D. F. 
observar en el análisis de políticas públicas:

Diseño:

$\mathrm{Su}$ diseño se compone por aquella serie de pasos y toma de decisiones tendientes a modelar una política pública capaz de solucionar la problemática en combate.

Entre los criterios para la toma de decisiones durante la vida de la política pública se encuentran los contrastes entre la realidad y el diseño previo de la política, la adaptación de la política a situaciones específicas que durante su diseño no se habían contemplado y situaciones de cambios de la realidad, donde el problema a resolver pueda ya no ser el mismo.

Implementación:

La implementación está ubicada en la sección final de la línea de producción de Políticas Públicas; su importancia versa en contextualizar en realidad los supuestos y objetivos que se generaron durante el diseño de la política pública.

La ejecución de una política pública está caracterizada por un conjunto de actividades individuales $\mathrm{u}$ organizativas que transforman conductas en el marco de un contexto prescriptivo establecido por una autoridad pública competente.

En este sentido la implementación de la política incluye también las capacidades administrativas y de gestión de los actores que llevan a cabo este proceso de puesta en marcha, a fin de superar los percances que generan las diferencias entre la teoría del diseño y la realidad de la implementación.

Capacidad presupuestaria:

Los fondos presupuestales constituyen uno de los principales pilares que sostiene a las Políticas Públicas; en específico, el financiamiento le proporciona a la Administración Pública la capacidad de acción.

En otras palabras, el presupuesto es el documento que transcribe y resume en términos numéricos el conjunto de las Políticas Públicas emanadas de la Política General del Gobierno. ${ }^{3}$

La brecha de la implementación:

3 Montagna, Antonio. Presupuesto y Políticas Públicas Administración públicaorte a los Gerentes en la Elaboración y Gestión del Presupuesto Público. Asociación de Administradores Gubernamentales. Segundo Congreso. www.ag.org.ar/2congreso/Ponencias/Montagna.pdf 
Consiste en la serie de obstáculos que, sin ser previstos, surgen una vez que los diseñadores han terminado su labor; es decir, es la disparidad que frecuentemente hay entre lo que se anuncia como política y lo que en realidad se ejecuta.

En otras palabras, al implementar una política pública, existe una alta probabilidad que lo que el contenido en papel como política sufra una modificación, cambio, ajuste o estrago mientras se hacen esfuerzos por ponerla en práctica, lo anterior derivado a una infinidad de factores entre lo que se encuentran:

- Falta de capacidad de los implementadores

- Falta de presupuesto

- Resistencia al cambio ${ }^{4}$

- Voluntad política

\section{La Función Jurisdiccional dentro de las Políticas Públicas}

Siendo la encargada de garantizar la prevalencia de las normas del Estado, la función esencial de la jurisdicción dentro de las Políticas Públicas, es la de constituirse en poder equilibrador entre el legislativo y el ejecutivo, controlando la observancia de las esferas competenciales, aunado a esto, mantiene la supremacía de la constitución vigilando que se respeten los procedimientos de elaboración de las leyes, y subordinando el orden jurídico a la norma fundamental. ${ }^{5}$

De lo anterior es posible desprender dos aspectos importantes:

- La función legislativa tiene un control directo de ciertos actos de la administrativa.

- El objetivo principal de la función administrativa es cumplir y hacer

4 Las políticas no solo proveen beneficios, sino que también imponen costos; crean ganadores, pero también perdedores. Una característica casi universal de las iniciativas de reforma política que crean ganadores y perdedores es que estos últimos tienen grandes incentivos para resistir el cambio y están plenamente conscientes de sus pérdidas potenciales, mientras que los ganadores no saben de los beneficios que habrán de recibir y pueden no estar bien organizados para forzar el cambio. Ibidem.

5 Huerta Ochoa, Carla. MECANISMOS CONSTITUCIONALES PARA EL CONTROL DEL PODER POLÍTICO, 2A.ED. Instituto de Investigaciones Jurídicas - U.N.A.M. México 
cumplir la ley, estableciendo los medios necesarios para esto.

La función jurisdiccional representa un control para los otros dos poderes, por medio de la revisión de sus actos respecto al orden constitucional.

Existe un ciclo de acción que corre a través de la ley y liga a las tres funciones en todo momento, esto es:

1.- La función legislativa emite la ley

2.- La función administrativa cumple la ley

3.- Cualquier controversia que lo anterior suscite, será resuelta por la función jurisdiccional.

La existencia de este primer aspecto el de los controles, es explicada por el profesor Karl Loewenstein, quien asegura que el detentador del poder es incapaz de limitarse a sí mismo en el abuso de este, en este sentido una de las principales funciones de la Constitución es limitar la concentración del poder absoluto en manos de un único detentador, al distribuir las diferentes funciones estatales entre varios detentadores del poder, con la finalidad de que uno controle los actos del otro, aspecto del que emerge la relación entre las sentencia y las políticas públicas.

De manera específica, la Función Jurisdiccional tiene la potestad de ejercer, a través de los juicios de materia constitucional, un control revisor sobre los actos de la Administración pública, cuando estos vulneren el contenido de la ley suprema.

En este sentido, al analizar el caso español, resulta interesante ver como la Constitución Ibérica le otorga la facultad expresa a Tribunales para que ejerzan un control sobre la Función Administrativa, al respecto se realiza la transcripción de la parte conducente del artículo 106 de la Ley Suprema de este país:

1. Los Tribunales controlan la potestad reglamentaria y la legalidad de la actuación administrativa, así como el sometimiento de ésta a los fines que la justifican.

Es importante mencionar que los efectos puntuales de la intervención de las sentencias o las jurisprudencias en la política pública son los siguientes: 
- Crear políticas públicas

- Modificar políticas públicas

- Extinguir políticas públicas

- Exigir el cumplimiento de las políticas públicas

Por último se considera que este fenómeno en específico se origina debido a que las funciones sociales del Estado se han ampliado a áreas tales como salud, vivienda, educación, trabajo, seguridad social, consumo o promoción de la participación de grupos sociales vulnerables. Sin embargo, ello no se ha traducido necesariamente, desde el punto de vista técnico, en la configuración concreta de derechos.

Lo anterior debido a que, en la mayoría de los Estados, las políticas sociales no han alcanzado la garantía de los derechos; por el contrario, se han desarrollado políticas públicas encaminadas a operar como concesiones revocables y discrecionales, que más que igualar a los desiguales, han funcionado como medidas de control de pobres ${ }^{6}$.

Al respecto Víctor Abramovich y Christian Courtis, siguiendo las ideas de Luigi Ferrajoli, comentan que aunque un estado cumpa con la satisfacción de determinadas necesidades o intereses tutelados por un derecho social, ningún observador podría afirmar que los beneficiados por la conducta estatal gozan de este derecho como derecho subjetivo, hasta en tanto verificar si la población se encuentra en condiciones de demandar judicialmente la prestación del Estado ante un eventual incumplimiento ${ }^{7}$.

\section{Las sentencias en el ámbito de las Políticas Públicas}

Montesquieu estima que no puede existir la libertad sino bajo el manto protector

6 Pisarello, Gerardo. Los derechos sociales y sus garantías. Elementos para una reconstrucción. Editorial Trotta, Madrid, 2007.

7 Abramovic, Víctor y Courtis, Christian. Los derechos sociales como derechos exigibles. Ed. Trotta. España. 2002. 
de las leyes, por otro lado Rousseau manifiesta que la ley surge de la libertad. ${ }^{8}$

A pesar de ser contradictorios, ambos autores hablan de la libertad y la ley como principios fundamentales del estado. La libertad de la que hablan, no puede surgir espontáneamente de la ley, sino que es garantizada y tutelada por los tribunales al resolver, bajo el imperio de la ley y en ejercicio de la potestad jurisdiccional, los conflictos de intereses que alteran el orden jurídico, fundamentalmente aquellos que surgen entre los gobernantes y gobernados.

En este sentido, es posible entender que los tribunales, a través de la aplicación de la ley, son los protectores de la libertad, de manera específica a través del ejercicio de su función jurisdiccional, sin embargo, la mayoría de las sentencias tienen efectos únicamente para quienes fueron litigantes en el proceso judicial.

Por otro lado, el orden constitucional del Estado mexicano ha abierto la puerta a sentencias de efectos generales o legislación negativa.

Estas sentencias tienen su origen cuando un Tribunal Constitucional Suprema Corte de Justicia de la Nación en el caso mexicano'- evalúa en abstracto la compatibilidad constitucional de normas generales, cuyo juicio afirmativo impone la consecuencia de la eliminación de dichas normas generales, se trata de un órgano encargado de expulsar normas generales, esto es, de derogar normas irregulares; este órgano no desempeña una función jurisdiccional común, sino de legislación negativa por la razón de que sus sentencias son, en realidad, actos de derogación de leyes. ${ }^{10}$

Por tanto, los efectos de este tipo de sentencias, consideradas como constitutivas, no es declarar las leyes inexistentes, sino constituirlas invalidas, dada la actualización de un vicio de anulabilidad de las mismas.

En específico, dentro del Estado mexicano, estas sentencias se derivan de

\footnotetext{
8 Armienta Calderón, Gonzalo. Los conceptos de jurisdicción y competencia. Instituto de investigaciones jurídicas - UNAM. www.juridicas.unam.mx/publica/librev/rev/facdermx/cont/.../cnt5.pdf

9 En este sentido, con base en lo señalado por los artículos 94, 103 y 107 de la Constitución Mexicana, el Poder Judicial de la Federación representa al guardián de la Constitución, el protector de los derechos fundamentales y el árbitro que dirime las controversias, manteniendo el equilibrio necesario que requiere un Estado de Derecho. Suprema Corte de Justicia de la Nación ¿Qué es e SCJN? https://www.scjn.gob.mx/conocelacorte/Paginas/ Que_es_la_SCJN.aspx

10 García Sarubbi, David. La difícil declaración entre una declaratoria de inconstitucionalidad erga omnes y sus efectos prácticos en México. Instituto de Investigaciones Jurídicas - Universidad Nacional Autónoma de México. http://www.revistas.unam.mx/index.php/cuc/article/view/23368
} 
Acciones de Inconstitucionalidad, Controversias Constitucionales y a partir del 2013-dos mil trece, del Juicio de Amparo por medio de la Declaratoria General de Inconstitucionalidad.

Es importante señalar que se requiere cumplir ciertos requisitos para que las sentencias derivadas de los juicios en comento, tengan efectos generales; para el caso de las dos primeras que la Suprema Corte de Justicia actuando en Pleno por mayoría de ocho votos o más, declare la inconstitucionalidad de normas generales $^{11}$.

Para el caso del juicio de amparo, la Declaratoria General de Inconstitucionalidad, opera cuando de la Suprema Corte de Justicia de la Nación, en los juicios de amparo indirecto en revisión, establezcan jurisprudencia por reiteración, en la cual se determine la inconstitucionalidad de la misma norma general $^{12}$.

Por otro lado, existen sentencias de efectos entre las partes pero que materialmente pueden tener efectos generales, para efectos del presente trabajo, se hablará de las sentencias derivadas del juicio de amparo indirecto.

Podría pensarse que este tipo de decisiones no tienen efectos generales, sin

11 ...la Suprema Corte de Justicia actuando en Pleno, declara la inconstitucionalidad de normas generales por mayoría de ocho votos o más, la declaratoria siempre implica la invalidez de dichas normas con efectos generales; estos invalidarán en forma total el ordenamiento normativo o la norma correspondiente, cuando la Federación demande y pruebe la inconstitucionalidad de normas estatales (o del Distrito Federal), o municipales; o cuando un Estado haga lo mismo en contra de normas municipales, mientras que cuando un Municipio demanda y prueba la inconstitucionalidad de normas generales de carácter federal o estatal, o cuando un Estado actúa en igual forma respecto de normas generales de la Federación, la declaratoria de invalidez, aunque también tiene efectos generales, éstos no llegan a nulificar totalmente el ordenamiento o la disposición de que se trata, sino que las consecuencias invalidatorias sólo benefician al ente actor, pero sigue rigiendo para todos los demás. RECURSO DE RECLAMACIÓN 85/98-PL, RELATIVO A LA CONTROVERSIA CONSTITUCIONAL 4/98. AYUNTAMIENTO DEL MUNICIPIO DE PUEBLA Y OTROS MUNICIPIOS DEL ESTADO DE PUEBLA.

12 Cuando el pleno o las salas de la Suprema Corte de Justicia de la Nación, en los juicios de amparo indirecto en revisión, establezcan jurisprudencia por reiteración, en la cual se determine la inconstitucionalidad de la misma norma general, se procederá a la notificación a que se refiere el tercer párrafo de la fracción II del artículo 107 de la Constitución Política de los Estados Unidos Mexicanos.

Una vez que se hubiere notificado al órgano emisor de la norma y transcurrido el plazo de 90 días naturales sin que se modifique o derogue la norma declarada inconstitucional, el pleno de la Suprema Corte de Justicia de la Nación emitirá la declaratoria general de inconstitucionalidad correspondiente siempre que hubiera sido administración públicarobada por mayoría de cuando menos ocho votos. Ley de Amparo, Artículo 232. 
embargo, la sentencia de amparo es una norma individual creada por el juez, cuyo cumplimiento es obligatoria para las autoridades que fueron señaladas como responsables, siendo el propio órgano jurisdiccional quien tiene las facultades necesarias para hacer cumplir sus determinaciones ${ }^{13}$.

En este sentido, los efectos de la concesión del amparo serán restituir al gobernado en el goce de sus derechos humanos violados, actualizándose este efecto en obligaciones para la autoridad de llevar a cabo los actos necesarios para cumplir el objetivo de la sentencia.

Dichos actos, por emanar de autoridades, tienen en la mayoría de los casos, efectos generales, por ejemplo, cuando un ciudadano imposibilitado físicamente para caminar, acude a una oficina de la función administrativa y encuentra imposible el acceso a esta por carecer de rampas y accesos especiales para personas discapacitadas, siendo esto violatorio de sus derechos de petición, igualdad y equidad.

En este caso, el ciudadano podría presentar una demanda de amparo para que sus derechos sean restituidos por medio de la creación de rampas y accesos especiales.

Resulta evidente que una sentencia de tales características, a pesar de haberse dictado para proteger solo los derechos de aquel que presentó la demanda, al ordenar modificaciones físicas al edificio donde reside la autoridad de que se trate, permitirá el acceso a toda persona discapacitada, traduciéndose esto en un beneficio general.

Casos como el descrito hacen que dichos mecanismos jurisdiccionales cobren importancia como control jurisdiccional de la administración, en específico, el amparo es un juicio que además de poder llegar a tener efectos generales, goza de las siguientes características:

Cercanía al ciudadano.-El amparo es un mecanismo que se encuentra al alcance de los ciudadanos, ya que cualquier persona que estime que le fue violentado un derecho fundamental estará legitimado para activar este control jurisdiccional.

Esto se traduce en que todo ciudadano tiene la capacidad de auditar los

13 Cruz Quiroz, Osmar Armando. Los efectos generales de las sentencias constitucionales. Instituto de Investigaciones Jurídicas - U.N.A.M. biblio.juridicas.unam.mx/libros/6/2559/18.pdf 
actos de la función administrativa cuando tenga relación con este.

Mayor cantidad de amparos que juicios de alcance general.- Debido a que cualquier ciudadano puede acceder a este juicio constitucional, hay más cantidad de amparos que de Acciones de Inconstitucionalidad o Controversias Constitucionales, lo que se traduce en un mayor impacto a la función administrativa, aunado a que existen más juzgadores que pueden conocer del juicio de amparo.

Autonomía.- El juicio de amparo, debido a tener el objetivo de proteger derechos fundamentales y ser presentado por ciudadanos comunes, no está sujeto a intereses políticos ni gubernamentales, tal como es el caso de las acciones de inconstitucionalidad y controversias constitucionales, que son juicios que derivado de los sujetos que están legitimados para presentarlos -órdenes de gobierno y autoridades-, pueden obedecer a muchos casos a factores de poder.

Alcance material y trascendencia colateral.- El primer antecedente que se encuentra en el estudio de este tema es proporcionado por Woodrow Wilson, en su artículo "El estudio de la administración 1887", donde define la función administrativa y establece de manera tajante que el actuar administrativo debe estar sujeto al orden constitucional.

Por otro lado, el juez norteamericano David L. Bazelon -década de los 70 's-, al resolver un asunto referente a la regulación de los niveles de plomo en las gasolinas -donde mediante una sentencia se le obliga a la administración pública a modificar las regulaciones y los procesos para la elaboración de combustibles-, realizó una reflexión que lo llevó a detectar una relación directa entre los tribunales y la administración pública.

De manera específica, Bazelon, argumenta que el gobierno tiene la facultad de regular el aire que respiramos, los alimentos que comemos, y el agua que bebemos en busca de rastros de químicos que causan cáncer y otras sustancias nocivas; que hace juicios sobre la seguridad de la energía de plantas nucleares y las drogas de potencia; incluso establece normas sobre el lugar de trabajo para el ruido, a fin de prevenir la sordera, y para la luz, para evitar ceguera; todo esto en busca de prevalencia de los derechos fundamentales de las personas. 
Resulta evidente que estas decisiones requieren conocimientos científicos y técnicos, por lo que el proceso de toma de decisiones ha sido delegado a los administradores públicos; siendo ordenado por el Congreso que sus actos, debido a su importancia y trascendencia a la esfera jurídica de los gobernados, sean revisados por la autoridad judicial, a fin de comprobar su apego a las normas.

En este sentido Bazelon establece, de manera literal, lo siguiente:

El auge del debido proceso ha traído peticiones de revisión judicial de presuntos actos ilegales de las escuelas, los hospitales -de hecho, de todas partes de los procesos administrativos. El crecimiento de la promoción pública -por individuos, el programa de servicios legales y bufetes de abogados de interés público -ha impulsado esta expansión de las actividades de la Corte, que se refiere a veces como "La revolución del debido proceso" 14 .

En otras palabras, la Constitución y las leyes establecen la existencia de derechos para las personas, cuya aplicación se pretende realizar a través de las Políticas Públicas, que en todo momento deberán apegarse a los procesos ordenados por los dispositivos jurídicos.

Sin embargo, la puesta en práctica de estos derechos no siempre es capaz de cumplir el objetivo de la ley, ya que existen ocasiones en que las políticas públicas no mantienen concordancia con el marco normativo, ya sea por desatención, falta de capacidad, o incluso por intransigencia de quien las elabora, supuesto donde la Función Jurisdiccional del Estado, órgano del que emanan las decisiones judiciales, se hará cargo de ajustar el actuar administrativo al marco normativo.

Es en este aspecto específico donde se aprecia un impacto de las sentencias en la actividad de la administración pública y sus Políticas Públicas, a manera de corrector -ya que el juzgador no puede omitir su opinión respecto a los actos administrativos, sino que interviene únicamente como resolutor de conflictos-, para asegurarse que todo acto de autoridad administrativa ${ }^{15}$, además de respetar el

14 L. Bazelon, David - United States Court of Administración públicapeals for the District of Columbia Circuit -. The Impact of the Courts on Public Administration. Indiana Law Journal http://www.repository.law.indiana. edu/ilj/vol52/iss $1 / 4 /$.

15 Autoridad.- La que dicta, ordena, ejecuta o trata de ejecutar el acto que crea, modifica o extingue situaciones 
debido proceso, no vulnere los derechos fundamentales de los gobernados.

Así, los jueces, como guardianes del orden constitucional, desarrollan un doble papel, ya que además de impartir justicia son capaces de rediseñar las políticas públicas, a través del control judicial de los actos administrativos, aspecto que les permite participar en el diseño e implementación de Políticas públicas, rompiendo el monopolio que en este sentido habían venido teniendo los Administradores Públicos.

Por último, antes de comenzar el análisis de este fenómeno en la realidad, se atiende al núcleo esencial de los derechos fundamentales, por ser aquel elemento que el juez debe preservar y cuya consecuencia es el control de las políticas públicas.

\section{Núcleo esencial de Los Derechos Fundamentales}

Los derechos fundamentales son considerados como tales en la medida en que constituyen instrumentos de protección de los intereses más importantes de las personas, puesto que preservan los bienes básicos necesarios para poder desarrollar cualquier plan de vida de manera digna ${ }^{16}$.

Ahora bien, el contenido esencial de los derechos supone una frontera que el legislador no puede cruzar, delimita un terreno que la ley limitadora no puede invadir sin incurrir en inconstitucionalidad, por lo que señala un límite más allá del cual no es posible la actividad limitadora de los derechos fundamentales y de las libertades públicas. En otras palabras, el tema fundamental de un derecho es un límite al poder del legislador ${ }^{17}$.

En este sentido, el núcleo esencial de un derecho fundamental es aquel

jurídicas en forma unilateral y obligatoria; u omita el acto que de realizarse crearía, modificaría o extinguiría dichas situaciones jurídicas. Ley de Amparo, artículo 5.

16 Carbonell, Miguel. Los derechos fundamentales en México. Instituto de Investigaciones Jurídicas U.N.A.M. http://biblio.juridicas.unam.mx/libros/libro.htm?1=1408

17 Lorenzo Rodríguez-Armas, Magdalena. El problema del contenido esencial de los derechos fundamentales en la doctrina española y su tratamiento en la jurisprudencia constitucional. http://publica.webs.ull.es/upload/ REV\%20ANALES/13-1996/03\%20(Magdalena\%20Lorenzo\%20Rodr\%C3\%ADguez-Armas).pdf. 
elemento que en caso de limitarse, eliminarse o modificarse, desnaturalizaría al derecho, esto es que el derecho se convierte en otro derecho o simplemente deja de existir. Es por ello que la Administración pública o cualquier otra función de gobierno, de ninguna manera pueden interferir con este contenido primordial de los derechos humanos.

Ahora bien, es posible que factores como la excesiva carga de trabajo o la poca profesionalización de los servidores públicos, por mencionar algunos, provoquen que el actuar administrativo, desarrollado a través de políticas públicas, vulnere los Derecho Fundamentales de los ciudadanos, al alejarse de lo ordenado por las normas, entre ellas la constitucional.

\section{Amparo en revisión 323/2014 -Mexicanos primero vs Auditoría Superior de la Federación-}

En sus informes de resultados del Fondo de Aportaciones para la Educación Básica y Normal 2009 y 2010, la Auditoría Superior de la Federación determinó que existían irregularidades como el pago indebido a comisionados sindicales y otras erogaciones entregadas de manera ilegal a las secciones sindicales por un monto de $\$ 6,769,287$ pesos. Una vez determinadas estas irregularidades, la ASF no inició todos los procedimientos administrativos y/o penales en contra de los responsables de dar y recibir de manera ilegal dichos recursos públicos, es decir, no ejerció todas sus facultades en materia de fiscalización de la cuenta pública de recursos educativos.

En respuesta a lo anterior, en Febrero del 2013, la asociación civil "Aprender Primero"-dependiente de "Mexicanos Primero"- presentó una demanda de amparo en contra de la Auditoría Superior de la Federación y varias autoridades ya que se consideró que el no ejercicio de facultades en materia de fiscalización de los recursos para la educación, es violatorio del Derecho a la Educación.

El juez de distrito que primero conoció el asunto declaró improcedente el juicio de amparo, pues determinó que "Aprender Primero" carecía de interés legítimo $^{18}$.

18 INTERÉS LEGÍTIMO. CONTENIDO Y ALCANCE PARA EFECTOS DE LA PROCEDENCIA DEL 
Acto seguido se interpuso un recurso de revisión ante la Suprema Corte de Justicia de la Nación quien resolvió que "Aprender Primero" sí tiene interés legítimo para acudir al juicio de amparo, ya que su objeto social es precisamente la defensa del derecho a la educación y tanto la Constitución como diversos tratados internacionales reconocen la posibilidad de realizar este tipo de intervención.

De acuerdo con los resolutivos, la Primera Sala del Supremo Tribunal Mexicano ordenó a la ASF llevar a cabo todas las acciones necesarias para cumplir con las facultades que tiene en materia de fiscalización de recursos en materia de educación, incluyendo iniciar y concluir los procedimientos de responsabilidad en contra de los servidores públicos federales y locales que hayan participado en el desvío de los recursos públicos o en su caso expresar, fundando y motivando, en los casos en los que no inicie el procedimiento correspondiente ${ }^{19}$.

Lo anterior, aplicado al presente estudio se traduce en una transformación del derecho a la educación de calidad, que si bien ya se trataba de un derecho constitucional, a través de la resolución en cita, se le dotó de mayores elementos para ser exigible y justiciable.

Por otro lado se trata de una sentencia que somete a la administración pública a ejercer sus actos en respeto a los derechos humanos, en este caso el derecho a la educación.

\section{Amparo en revisión 44/2009 -Issteleon y sus Políticas Discriminatorias-}

\section{La Ley que crea el ISSSTELEON, órgano homologo al Instituto de Seguridad y}

JUICIO DE AMPARO (INTERPRETACIÓN DEL ARTÍCULO 107, FRACCIÓN I, DE LA CONSTITUCIÓN POLÍTICA DE LOS ESTADOS UNIDOS MEXICANOS). Dicho interés legítimo se refiere a la existencia de un vínculo entre ciertos derechos fundamentales y una persona que comparece en el proceso, sin que dicha persona requiera de una facultad otorgada expresamente por el orden jurídico, esto es, la persona que cuenta con ese interés se encuentra en administración públicatitud de expresar un agravio diferenciado al resto de los demás integrantes de la sociedad, al tratarse de un interés cualificado, actual, real y jurídicamente relevante, de tal forma que la anulación del acto que se reclama produce un beneficio o efecto positivo en su esfera jurídica, ya sea actual o futuro pero cierto.

19 Mexicanos Primero A.C. ¿El derecho a la educación no era ya un derecho constitucional?http://www. mexicanosprimero.org/index.php/educacion-en-mexico/nuestra-opinion/item/el-derecho-a-la-educacion-noera-ya-un-derecho-constitucional 
Servicios Sociales de los Trabajadores del Estado, en el estado de Nuevo León, incluye el artículo 4 que señala de manera literal, lo siguiente:

Art. 4.- No se consideran sujetos de incorporación al régimen que establece esta ley, los servidores públicos que:

IV.- Al ingresar por primera vez al servicio hayan cumplido 50 años de edad.

V.- Por resultado del examen médico practicado por el instituto se determine su no incorporación

Ello implica la exclusión de la afiliación a aquellos trabajadores mayores de 50 años que ingresen al servicio público por primera vez y a aquellos que sufran de una enfermedad preexistente

Desde 1993 dicha disposición ha rechazado a miles de trabajadores públicos, discriminándolos a ellos y a sus familias, violentándoles sus derechos constitucionales en lo referente a la seguridad social, salud y trabajo

Dicha práctica atenta de forma directa los derechos humanos de igualdad y no discriminación, así como a los derechos fundamentales del trabajo, seguridad social y acceso a la salud.

En este sentido, en 2010 la Suprema Corte de Justicia de la Nación, a través del amparo en revisión 44/2009 por primera vez se pronunció respecto a esta práctica declarándola como inconstitucional por restringir la afiliación a los trabajadores públicos que sufren de alguna preexistencia y quieran incorporarse a un sistema de salud como lo es en este caso el ISSSTELEON.

La Primera Sala de la Suprema Corte de Justicia de la Nación resolvió por unanimidad otorgándole la razón al quejoso por considerar se violentan los artículos 1, 4 y 123 apartado B, fracción IX, de la Constitución Política de los Estados Unidos Mexicanos y calificó de discriminatorio el artículo sexto del Reglamento de afiliación de la Ley de ISSSTESON, y señalando también que mientras la autoridad responsable no modifique este precepto se abstenga de aplicarlo. Considerándose estos efectos materialmente generales.

La Suprema Corte de Justicia de la Nación generó con ello nuevos criterios jurídicos en cuanto a discriminación y acceso a los servicios de salud, que se resumen en tres tesis, que hoy en día son criterios orientadores y de precedente referencial para los jueces:

SEGURIDAD Y SERVICIOS SOCIALES DE LOS TRABAJADORES DEL ES- 
TADO DE SONORA. EL ARTÍCULO 6 DEL REGLAMENTO PARA LOS SERVICIOS MÉDICOS DEL ISSSTESON, AL ESTABLECER QUE PARA TENER ACCESO AL SERVICIO MÉDICO LOS TRABAJADORES DE NUEVO INGRESO O REINGRESO DEBERÁN ACREDITAR QUE GOZAN DE BUENA SALUD, VIOLA EL ARTÍCULO 10. DE LA CONSTITUCIÓN GENERAL DE LA REPÚBLICA.

SEGURIDAD Y SERVICIOS SOCIALES DE LOS TRABAJADORES DEL ESTADO DE SONORA. EL ARTÍCULO 6 DEL REGLAMENTO PARA LOS SERVICIOS MÉDICOS DEL ISSSTESON, AL ESTABLECER QUE PARA TENER ACCESO AL SERVICIO MÉDICO LOS TRABAJADORES DE NUEVO INGRESO O REINGRESO DEBERÁN ACREDITAR QUE GOZAN DE BUENA SALUD, VIOLA EL ARTÍCULO 4o., TERCER PÁRRAFO, DE LA CONSTITUCIÓN GENERAL DE LA REPÚBLICA.

SEGURIDAD Y SERVICIOS SOCIALES DE LOS TRABAJADORES DEL ESTADO DE SONORA. EL ARTÍCULO 6 DEL REGLAMENTO PARA LOS SERVICIOS MÉDICOS DEL ISSSTESON, AL ESTABLECER QUE PARA TENER ACCESO AL SERVICIO MÉDICO LOS TRABAJADORES DE NUEVO INGRESO O REINGRESO DEBERÁN ACREDITAR QUE GOZAN DE BUENA SALUD, VIOLA EL ARTÍCULO 123, ADMINISTRACIÓN PÚBLICAARTADO B, FRACCIÓN XI, INCISO A), DE LA CONSTITUCIÓN GENERAL DE LA REPÚBLICA.

\section{Acción pública de inconstitucionalidad C355/2006 de la Corte Constitucional De Colombia-Despenalización del aborto-}

¿Cómo era originalmente la política pública?

Los numerales de la ley número 599 de 2000 -Código Penal de Colombiaprohibían el aborto, estableciendo lo siguiente:

CAPITULO CUARTO

Del aborto

ART. 122.-Aborto. La mujer que causare su aborto o permitiere que otro se lo cause, incurrirá en prisión de uno (1) a tres (3) años. 
A la misma sanción estará sujeto quien, con el consentimiento de la mujer, realice la conducta prevista en el inciso anterior.

ART. 123.-Aborto sin consentimiento. El que causare el aborto sin consentimiento de la mujer o en mujer menor de catorce años, incurrirá en prisión de cuatro (4) a diez (10) años.

ART. 124.-Circunstancias de atenuación punitiva. La pena señalada para el delito de aborto se disminuirá en las tres cuartas partes cuando el embarazo sea resultado de una conducta constitutiva de acceso carnal o acto sexual sin consentimiento, abusivo, de inseminación artificial o transferencia de óvulo fecundado no consentidas.

De lo anterior es posible desprender que la política pública respecto al aborto era penar bajo cualquier circunstancia la interrupción del embarazo, tanto para la mujer como para el médico que participara en dicha obstrucción a la vida, aun tratándose de aquellos casos en los que el embarazo se derive de un abuso sexual o cualquier medio que vaya en contra del consentimiento de la mujer, situación en que solo se preveía una disminución de la pena.

En este sentido, varios ciudadanos presentaron diversas demandas de juicio de Acción Pública de Inconstitucionalidad, por medio de las cuales se argumentaba que los ya citados artículos 122, 123 y 124 del Código Penal colombiano, vulneraban el derecho a la dignidad, la autonomía reproductiva y al libre desarrollo de la personalidad, derechos establecidos en los artículos $1^{\circ}, 16$ y 42 de la Constitución de aquel país.

En el mismo sentido, se consideró que se violaban el derecho a la igualdad y a la libre determinación, el derecho a la vida, a la salud y a la integridad, el derecho a estar libre de tratos crueles inhumanos y degradantes y las obligaciones de derecho internacional de derechos humanos ${ }^{20}$.

En respuesta, la Corte consideró que corresponde al Congreso adoptar las medidas idóneas para cumplir con el deber de protección de la vida, y que sean

20 Artículo 1. Colombia es un Estado social de derecho, organizado en forma de República unitaria, descentralizada, con autonomía de sus entidades territoriales, democrática, participativa y pluralista, fundada en el respeto de la dignidad humana, en el trabajo y la solidaridad de las personas que la integran y en la prevalencia del interés general. Artículo 16. Todas las personas tienen derecho al libre desarrollo de su personalidad sin más limitaciones que las que imponen los derechos de los demás y el orden jurídico. Artículo 42. La familia es el núcleo fundamental de la sociedad. Se constituye por vínculos naturales o jurídicos, por la decisión libre de un hombre y una mujer de contraer matrimonio o por la voluntad responsable de conformarla. 
de su cargo; sin embargo esto no significa que estén justificadas todas las que dicte con dicha finalidad, porque a pesar de su relevancia constitucional la vida no tiene el carácter de un valor o de un derecho de carácter absoluto y debe ser ponderada con los otros valores, principios y derechos constitucionales.

El derecho a la vida supone la titularidad para su ejercicio y dicha titularidad, como la de todos los derechos está restringida a la persona humana, mientras que la protección de la vida se predica incluso respecto de quienes no han alcanzado esta condición.

Por otro lado, se reconoció que el Congreso dispone de un amplio margen de configuración de la política pública en relación con el aborto, sin embargo, dicho margen no es ilimitado.

Aún en el campo penal de dicha política pública, el legislador ha de respetar dos tipos de límites constitucionales. En efecto, al legislador penal, en primer lugar, le está prohibido invadir de manera desproporcionada derechos constitucionales $y$, en segundo lugar, le está ordenado no desproteger bienes constitucionales, sin que ello signifique desconocer el principio de que al derecho penal, por su carácter restrictivo de las libertades, se ha de acudir como última ratio.

En otras palabras, corresponde al legislador la decisión de adoptar disposiciones penales para la protección de bienes de rango constitucional como la vida; sin embargo, los derechos fundamentales y los principios constitucionales se erigen en límites a esa potestad de configuración, correspondiéndole a la Corte Constitucional, como guardiana de la integridad y supremacía de la Constitución, ejercer en estos casos el control sobre los límites que ella le ha impuesto al legislador, es decir, debe examinar si tales medidas legislativas presentan o no el carácter de restricciones constitucionalmente válidas.

No corresponde al juez constitucional determinar el carácter o la naturaleza de las medidas de protección que debe adoptar el legislador para proteger un bien jurídico concreto; se trata de una decisión de política pública reservada al poder que cuenta con legitimidad democrática para adoptar este tipo de medidas, siendo la intervención del juez constitucional a posteriori y exclusivamente para analizar si la decisión adoptada por el legislador no excede los límites de su potestad de configuración. 
Continúa la Corte estableciendo que la penalización del aborto en todas las circunstancias implica la completa preeminencia de uno de los bienes jurídicos en juego, la vida del nasciturus, y el consiguiente sacrificio absoluto de todos los derechos fundamentales de la mujer embarazada, lo que sin duda resulta a todas luces inconstitucional.

Dicha intromisión estatal en el libre desarrollo de la personalidad de la mujer y en su dignidad humana, privaría totalmente de contenido estos derechos $y$ en esa medida resulta manifiestamente desproporcionada e irrazonable.

Por lo anterior, en fecha 10 de Mayo de 2006, la Corte declaró ajustado a la Constitución el artículo 122 del Código Penal en el entendido que no se incurre en delito de aborto, cuando con la voluntad de la mujer, la interrupción del embarazo se produzca en los siguientes casos:

A) Cuando la continuación del embarazo constituya peligro para la vida o la salud de la mujer, certificado por un médico.

B) Cuando exista grave malformación del feto que haga inviable su vida, certificada por un médico.

C) Cuando el embarazo sea resultado de una conducta, debidamente denunciada, constitutiva de acceso carnal o acto sexual sin consentimiento, abusivo, o de inseminación artificial o de transferencia de óvulo fecundado no consentidas, o de incesto.

Sin embargo, la Corte hace la aclaración de que además de estas hipótesis, el legislador puede prever otras en las cuales la política pública frente al aborto no pase por la sanción penal, atendiendo a las circunstancias en las cuales éste es practicado, así como a la educación de la sociedad y a los objetivos de la política de salud pública.

\section{Conclusiones}

Una vez finalizado el presente estudio, se presentan los principales resultados de cada una de las ideas planteadas a lo largo de las anteriores páginas.

1. Las funciones legislativa y administrativa son las encargadas de 
formular las políticas públicas, a través de sus facultades para expedir disposiciones generales, por otro lado, la función administrativa es también la encargada de materializar o poner en práctica el contenido de la política pública.

Por su parte, la función jurisdiccional se encarga de impartir justicia, entendido esto como garantizar el cumplimiento del contenido de la constitución y las leyes; derivado de dicha facultad, puede examinar si los actos de las otras dos funciones, incluidas las políticas públicas, se apeguen a estas normas.

2. A pesar de que se reconoce la existencia de la revisión jurisdiccional sobre todo tipo de actos de las funciones legislativa y administrativa, incluidas las políticas públicas y su ejecución, esta facultad de revisión de la autoridad juzgadora ha sido inadvertida en la mayoría de los casos por los estudiosos de los asuntos públicos.

3. El actuar de cualquiera de las funciones de gobierno -Legislativa, Administrativa y Jurisdiccional-, debe estar apegado a la garantía de legalidad, es decir, que sus actos deben estar adheridos a lo ordenado por la Constitución y por las leyes, sin embargo factores como el exceso de trabajo, falta de presupuesto, carencia de personal capacitado o ignorar el factor jurisdiccional así como el contenido normativo, pueden provocar que los actos emanados de las funciones citadas sean contrarios a las normas, aspecto que se presenta con frecuencia en la administración pública y sus políticas públicas.

4. Existe una incorrecta interpretación de las disposiciones generales y del alcance de las mismas, en específico de los derechos y principios constitucionales por parte de la administración; aspecto que provoca que los actos emanados de la misma violenten los derechos fundamentales y principios que en ella se contienen. Esta problemática que puede ser solucionada con la observación de las sentencias y la incorporación de la jurisprudencia.

5. Las sentencias, al tratarse de actos que declaran derechos, aplicando las normas a casos concretos, constituyen normas individuales que disciplinan el actuar de las partes; cuando la autoridad administrativa es 
parte dentro de un juicio porque sus actos no cumplen con los requisitos de ley, los tribunales le obligan a apegar sus políticas públicas al orden constitucional y a las leyes emanadas del mismo. En este sentido el control jurisdiccional de las políticas públicas se vuelve general y es especialmente pertinente en contextos democráticos en los cuales la Constitución es detallada y existe una superposición de las competencias sobre las que tiene responsabilidad el gobierno.

6. Formalmente, las sentencias que tienen un impacto tangible para la política pública son las denominadas como "de efectos generales", ya que se encargan de expulsar normas, sin embargo las decisiones derivadas de los juicios de amparo indirecto poseen efectos materialmente generales y por tratarse de mecanismos más cercanos al ciudadano, constituyen un medio de control jurisdiccional mucho más efectivo que las controversias constitucionales y las acciones de inconstitucionalidad.

Así, los tribunales desarrollan un doble papel, ya que además de impartir justicia son capaces de rediseñar las políticas públicas a través del control judicial de los actos administrativos, aspecto que les permite participar en el diseño e implementación, rompiendo el monopolio que en este sentido habían venido teniendo los administradores públicos.

7. La facultad revisora de los tribunales se puede dar por la vulneración al principio del debido proceso, que garantiza que las políticas públicas se apeguen a lo ordenado por las normas respecto a su proceso de formulación y ejecución, así como a la competencia que la autoridad administrativa tenga para emitir la política pública; o porque su contenido de fondo sea contrario a lo ordenado por la constitución o por las leyes que de ella emanen. Dicha revisión de los tribunales hacia las políticas públicas debe ser incitada por un actor que considere que las faltas que cometa la administración le están vulnerando algún derecho. Por esto los tribunales se enfrentan a la limitante de depender de un tercero para iniciar su revisión de las políticas públicas.

8. El control jurisdiccional ha comenzado a adquirir protagonismo en los Estados debido a la tendencia de que el contenido programático de la Constitución tenga una naturaleza exigible ante los tribunales. En este 
sentido, cuando un derecho sea definido minuciosamente, de modo que contemple todos los deberes específicos que de él se desprenden, serán mayores las limitaciones de la política pública que pretenda desarrollar el derecho, y menores sus márgenes de apreciación reduciendo los errores que se puedan presentar. En sentido contrario, cuando un derecho sea definido de manera vaga, la falta de precisión del objetivo que debe perseguir la política pública le permite al encargado de formularla, un amplio margen de actuación, supuesto donde los tribunales adquieren protagonismo para definir de manera precisa los derechos y ajustar las políticas públicas a tal definición.

9. Se reconoce que las funciones legislativa y administrativa, a través de su facultad de emitir disposiciones generales, tienen un amplio margen de configuración de la política pública. Sin embargo también se reconoce que dicho margen no es ilimitado, ya que el legislador ha de respetar límites constitucionales. En primer lugar, le está prohibido modificar el núcleo duro de los derechos constitucionales, en segundo lugar, le está ordenado no desproteger bienes constitucionales y en tercer lugar no puede vulnerar principios constitucionales. En este sentido no corresponde a los tribunales determinar las medidas de protección que debe adoptar el legislador o el administrador para proteger un bien jurídico concreto, ya que esto se trata de una decisión de política pública reservada al poder que cuenta con legitimidad democrática para adoptar este tipo de medidas, siendo la intervención de los tribunales exclusivamente para analizar si la decisión adoptada no excede los límites de su potestad de configuración.

10. Una vez que los tribunales han protegido los derechos y principios constitucionales a través del dictado de sus sentencias, es importante aclarar que se salvaguarda la facultad de los diseñadores de políticas públicas para seguir modificando dicha política según lo considere conveniente o necesario, siempre y cuando no se modifique lo ya resguardado por el ejercicio jurisdiccional.

11. Los principales efectos de la variable jurisdiccional sobre las políticas públicas son: crear políticas públicas en aquellos casos en que la 
administración omita materializar cierto derecho, modificar políticas públicas en caso de que una parte de ellas vulnere la Constitución o desatienda lo ordenado en las leyes, eliminar políticas públicas en caso de que su contenido vulnere de manera total las normas o derechos en ellas contenidos y exigir el cumplimiento de políticas públicas en aquellos casos en los que el administrador público sea omiso en cumplir lo ordenado por las normas. Aun a esto, los administradores públicos pueden incurrir en responsabilidad por crear o implementar una política pública que vulnere derechos o principios constitucionales.

12. El control jurisdiccional de las políticas implica un desencadenamiento de consecuencias que impactan en aspectos: Jurídicos - por medio de la expedición de leyes y reglamentos para ajustar la política pública-; Económicos -debido a la modificación de los presupuestos, que no estaba contemplada por la administración, suponiendo esto una externalidad negativa a la política pública-; Institucionales -ya que implica cambios en la forma de actuar e incluso en los organigramas de las organizaciones que se encarguen de poner en práctica la política pública-; Políticos -ya que la nueva configuración de la política impacta los objetivos de la administración en cargo, supuesto que a su vez puede reducir su credibilidad y tener consecuencias negativas desde el punto de vista electoral o en sus relaciones con otros órganos u órdenes de gobierno- y Sociales -ya que la sociedad puede responder de diversas formas ante el cambio de una política pública, dependiendo esto de la parte de la sociedad a la que estaba dirigida la política y el sentido de la modificación-.

\section{Bibliografía:}

(Art. 241 C.P. -Funciones de la Corte Constitucional; numerales 4, 8 y 10 y parágrafo): Clase de sentencia emitida por la Corte Constitucional en la que se manifiesta que una Ley es contraria a la Constitución Nacional y por lo tanto debe des administración pública arecer total o parcialmente del orden jurídico. Senado de la República de Colombia. http://www.senado.gov.co/glosario/Glosario-1/I/Inexequibilidad-19/ 
Aguirre Pangburn, Ruben. Las sentencias con efectos generales. Instituto de Investigaciones Jurídicas - Universidad Nacional Autónoma de México. http://biblio.juridicas.unam.mx/libros/7/3021/23.pdf. Aguirre Saldívar, Enrique. Los retos del Derecho Público en materia de Federalismo. Hacia la Integración Del Derecho Administrativo Federal. http://biblio.juridicas.unam.mx/libros/libro.htm?1=919 Armienta Calderón, Gonzalo. Los conceptos de jurisdicción y competencia. Instituto de investigaciones jurídicas - UNAM. www. juridicas.unam.mx/publica/librev/rev/facdermx/cont/.../cnt5.pdf Bacre, Aldo. Ejecución de sentencia, Argentina, Editorial la Rocca, 2010, P. 323.

Bardach, Eugene. Los ocho pasos para el análisis de Políticas Públicas. Un manual para la práctica. Ed. Centro de Investigación y Docencia Económicas - Miguel Ángel Porrúa. México. 1998 Banco interamericano de desarrollo. La política de las políticas públicas. www.iadb.org/res/publications/pubfiles/pubITO-2006_esp.pdf Banco interamericano de desarrollo. La política de las políticas públicas. www.iadb.org/res/publications/pubfiles/pubITO-2006_esp.pdf Briseño Sierra, Humberto. "El juicio ordinario civil. Doctrina, legislación y jurisprudencia mexicanas”. VolII S.N.E., Trillas México 1983. Caberzut Uribe, Adriana. Teoría de la nulidad del acto administrativo. www.tfjfa.gob.mx/.../pdf/teoriadelanulidaddelactoadministrativo. pdf

Chaires Zaragoza, Jorge. Mecanismos de participación ciudadana directa: Un análisis sobre su eficacia. Instituto de Investigaciones Jurídicas - Universidad Nacional Autónoma de México. México2012. http:// www.juridicas.unam.mx/publica/librev/rev/sufragio/cont/9/ens/ ens14.pdf

Corte Interamericana de Derechos Humanos. El acceso a la justicia como garantía de los derechos económicos, sociales y culturales. Estudio de los estándares fijados por el Sistema Interamericano de Derechos Humanos. III. Debido proceso administrativo y garantía de derechos sociales. http:/www.cidh.org/countryrep/AccesoDESC07sp/ 
Accesodesciii.sp.htm

Corilloclla, Pavel G. La justicia constitucional y las políticas públicas.

Una administración públicaroximación. http://www.expansiva.cl/ media/publicaciones/indagacion/documentos/20090707121202.pdf

Fleiner, Instituciones de Derecho Administrativo, versión española.

Editorial Labor. Barcelona (Enciclopedia de Ciencias Jurídicas y Sociales), 1933, pag. 16.

Flórez Muñoz, Daniel Eduardo. La acción pública de inconstitucionalidad como garantía del Estado constitucional en Colombia. Red de Revistas Científicas de América Latina y el Caribe, España y Portugal. http:// www.redalyc.org/articulo.oa?id $=94516586006$

García Castillo, Zoraida y Santiago Jiménez, Alejandro. Generalidades sobre la técnica jurídica para la elaboración de sentencias. Instituto de investigaciones jurídicas - UNAM. http://www.juridicas.unam. $\mathrm{mx} / \mathrm{publica} / \mathrm{rev} /$ indice.htm? $\mathrm{r}=$ facdermx $\& \mathrm{n}=241$

García Sarubbi, David. La difícil declaración entre una declaratoria de inconstitucionalidad erga omnes y sus efectos prácticos en México. Instituto de Investigaciones Jurídicas - Universidad Nacional Autónoma de México. http://www.revistas.unam.mx/index.php/cuc/ article/view/23368

Gómez, Lara, Cipriano. "Teoría general del proceso",. 9a ed. Harla, México, 1996.

Geog Fischbach, Oskar. Teoría General del Estado. Ed. Labor. 1934. España.

Grindle, M. (2009). "La brecha de implementación”. Política pública y democracia en América Latina. Mariñez F, y Garza, V (Coordinadores). Editorial Miguel Ángel Porrúa.

Hans Kelsen. El concepto de estado y la Psicología social. Instituto de InvestigacipnesJuridicas - U.N.A.M. biblio.juridicas.unam.mx/ libros/2/970/17.pdf

Huerta Ochoa, Carla. MECANISMOS CONSTITUCIONALES PARA EL CONTROL DEL PODER POLÍTICO, 2A.ED. Instituto de Investigaciones Jurídicas - U.N.A.M. México 
Jinesta, Ernesto. Debido proceso en la sede administrativa http://www. ernestojinesta.com/Debido $\% 20$ Proceso $\% 20$ en $\% 201 a \% 20$ Sede $\% 20$ Administrativa.pdf.

L. Bazelon, David - United States Court of Administración públicapeals for the District of Columbia Circuit -. The Impact of the Courts on Public Administration. Indiana Law Journal http://www.repository. law.indiana.edu/ilj/vol52/iss1/4/

La administración públicauente, Osvaldo. El diseño de las Políticas Públicas. http://biblio3.url.edu.gt/Libros/2011/sem_inter/4.pdf.

Lowenstein, Karl, Teoría de la Constitución, Barcelona, Ariel, 1986, pp. 232 y ss.

Manuel Luis Rodríguez U. Los procesos de toma de decisiones de las políticas públicas: una administración públicaroximación desde la Ciencia Política. http://gobiernoyadministracion.wordpress. com/2011/06/14/los-procesos-de-toma-de-decisiones-de-laspoliticas-publicas-una-administración públicaroximacion-desde-laciencia-politica/

Martínez Cerda, Nicolás. La Corte Constitucional y la Inconstitucionalidad de las normas constitucionales. Instituto mexicano del Amparo, México. 1995.

Maurer, Hartmut. Derecho Administrativo Alemán. Instituto de Investigaciones Jurídicas. Universidad Nacional Autónoma de México. México. 2012.

Ministerio de Protección Social República de Colombia. Universidad Nacional de Colombia. Implicaciones Éticas, Jurídicas y Medicas de la Sentencia C-355 de la Corte Constitucional. http://www.unal.edu. co/bioetica/documentos/conveniodoc/parte\%20interna $\% 20$ cartilla. pdf.

Ministerio de Protección Social República de Colombia. Universidad Nacional de Colombia. Implicaciones Éticas, Jurídicas y Medicas de la Sentencia C-355 de la Corte Constitucional. http://www.unal.edu. co/bioetica/documentos/conveniodoc/parte\%20interna $\% 20$ cartilla. pdf. 
Montagna, Antonio. Presupuesto y Políticas Públicas Administración públicaorte a los Gerentes en la Elaboración y Gestión del Presupuesto Público. Asociación de Administradores Gubernamentales. Segundo Congreso. www.ag.org.ar/2congreso/Ponencias/Montagna.pdf Mosquera Morales, Ariel. Comparativo de la elaboración de Políticas Públicas entre Eugene Bardach y Charles Lindlon. Universidad de Buenos Aíres. 2012. https:/www.academia.edu/4105682/ Comparativo_politicas_publicas_Lindlom_Bardach

Ovalle Favela, José. "Derecho procesal civil" $6{ }^{a}$ ed. Harla, México, 1994 p. 205.

Paolo Biscareti di Ruffa. Introcucción al derecho constitucional comparado, México, FCE, 1975.

Quiche-Ramiréz, Manuel Fernando. El control judicial de las políticas públicas como instrumento de inclusión de los Derechos Humanos. Instituto de Investigaciones Jurídicas - Universidad Nacional Autónoma de México. México. 2010. http://www.juridicas.unam. $\mathrm{mx} /$ publica/librev/rev/vniver/cont/121/cnt/cnt5.pdf

Roth, André-Noël. (2008, julio-diciembre). Perspectivas teóricas para el análisis de las políticas públicas: ¿de la razón científica al arte retórico? Estudios Políticos, 33, Instituto de Estudios Políticos, Universidad de Antioquia, 67-91.

Roth Deubel, André-Noël. Políticas Públicas, Formulación Implementación y Evaluación. Ediciones Aurora. Colombia. 2006. Straussman, Rosemary O'Leary y Jeffrey D. "El Impacto de los Tribunales sobre la Gestión Pública." Barry, Bozeman. La Gestión Pública. Su situación Actual. San Franciso, California: Fondo de Cultura Económica, 2006. 527.

Suprema Corte de Justicia de la Nación ¿Qué es e SCJN? https://www. scjn.gob.mx/conocelacorte/Paginas/Que_es_la_SCJN.aspx

Suprema corte de justicia de la nación, Manual del juicio de amparo, Ed.

Themis, $2^{\mathrm{a}}$ ed. México 2000.

Valdivielso del Real, Rocío. Análisis de Políticas Públicas. Universidad

Nacional de Educación a Distancia. Universidad Complutense. 
http://pendientedemigracion.ucm.es/info/eurotheo/diccionario/P/ politicas_publicas.htm

Wilson, Woodrow. El estudio de la administración. Clásicos de la Administración pública, México, Fondo de Cultura Económica, Colegio Nacional de Ciencias Políticas y Administración pública, A.C. 1999. P 74.

Women's Link Worldwide. Manual constitucional para la práctica de IVE - lineamientos constitucionales para el ejercicio del derecho al aborto en Colombia. http://www.womenslinkworldwide.org/pub_ manualIVE.html 
